haemophilia A treated with plasma-derived or recombinant Factor VIII: no proof of difference or proof of no difference? Semin Thromb Hemost 2014; 40: 269-70.

5. Stidham RW, Lee TC, Higgins PD, et al. Systematic review with network meta-analysis: the efficacy of anti-tumour necrosis factor-alpha agents for the treatment of ulcerative colitis. Aliment Pharmacol Ther 2014; 39: 660-71.

6. Messori A, Fadda V, Gatto R, Maratea D, Trippoli S. PubMed Commons (comment). Available at: http://www.ncbi.nlm.nih. gov/pubmed/24506179. Accessed February 12, 2014.

7. Reinisch W, Sandborn WJ, Hommes DW, et al. Adalimumab for induction of clinical remission in moderately to severely

\section{Letter: biological drugs for inducing remission in ulcerative colitis - authors' reply}

\author{
R. W. Stidham*, T. C. H. Lee ${ }^{\dagger}$, P. D. R. Higgins ${ }^{\star}$, A. R. \\ Deshpande*, D. A. Sussman ${ }^{\star}$, A. G. Singal ${ }^{\S}$, B. J. \\ Elmunzer ${ }^{\star}$, S. D. Saini ${ }^{\star \star \pi}$, S. Vijan ${ }^{\dagger, \pi} \&$ A. K. Waljee ${ }^{\star, \pi}$ \\ *Division of Gastroenterology and Hepatology, Department of Internal \\ Medicine, University of Michigan Health System, Ann Arbor, MI, \\ USA. \\ †University of Michigan, Ann Arbor, MI, USA. \\ \#University of Miami Miller School of Medicine, Miami, FL, USA. \\ $\S$ UT Southwestern Medical Center, Dallas, TX, USA. \\ "Ann Arbor Veterans Affairs Healthcare System, Ann Arbor, MI, USA. \\ E-mail: awaljee@med.umich.edu
}

doi:10.1111/apt.12724

SirS, We thank Maratea et al. for their insightful comments. ${ }^{1}$ Network meta-analyses (NMAs) are becoming increasingly common in the medical literature. Various analytic techniques are available for NMAs. In our study, ${ }^{2}$ we used a Bayesian-driven approach with uninformed priors and found only nonsignificant trends when comparing anti-tumour necrosis factor (TNF) agents for both remission and response.

We agree that it is important to differentiate between "no proof of difference" (i.e., an inconclusive result) and active ulcerative colitis: results of a randomised controlled trial. Gut 2011; 60: 780-7.

8. Norman G, Monteiro S, Salama S. Sample size calculations: should the emperor's clothes be off the peg or made to measure? BMJ 2012; 23: e5278.

9. Fadda V, Maratea D, Trippoli S, Messori A. Network metaanalysis. Results can be summarised in a simple figure. BMJ 2011; 23: d1555.

10. Bucher HC, Guyatt GH, Griffith LE, Walter SD. The results of direct and indirect treatment comparisons in meta-analysis of randomized controlled trials. J Clin Epidemiol 1997; 50: 683-91.

"proof of no difference" (i.e., equivalence) and find the results by Maratea and colleagues interesting. However, as the authors point out, their conclusions are based on an underlying assumption (margin of $12 \%$ ), which has a "certain degree of arbitrariness".

Thus, despite its sophistication, even this approach is also inherently inconclusive regarding definite superiority or equivalence among anti-TNF agents. Until more conclusive data are available, we believe that other factors such as preference, safety, cost and route of administration should dictate choice of anti-TNF agents. Ultimately, a randomised controlled trial among anti-TNF agents in $\mathrm{UC}$ is of practical size and should be performed.

\title{
ACKNOWLEDGEMENT
}

The authors' declarations of personal and financial interests are unchanged from those in the original article. ${ }^{2}$

\section{REFERENCES}

1. Maratea D, Fadda V, Trippoli S, et al. Letter: biological drugs for inducing remission in ulcerative colitis. Aliment Pharmacol Ther 2014; 39: 1242-4.

2. Stidham RW, Lee TCH, Higgins PDR, et al. Systematic review with network meta-analysis: the efficacy of anti-tumour necrosis factor-alpha agents for the treatment of ulcerative colitis. Aliment Pharmacol Ther 2014; 39: 660-71.

E-mail: ale.sartini@gmail.com

\section{doi:10.1111/apt.12705}

SIRS, We read with interest the review by Moran and colleagues on dermatological complications of immunosuppressive therapies for inflammatory bowel disease (IBD), particularly anti-tumour necrosis factor alpha (TNF $\alpha)$-in- 